\title{
The role of small- and medium-sized enterprises in the Dutch economy: an analysis using an extended supply and use table
}

\author{
Stephen Chong ${ }^{1}$, Rutger Hoekstra ${ }^{2}$, Oscar Lemmers ${ }^{1 *}$ (D) Ilke Van Beveren ${ }^{3,4}$, Marcel Van Den Berg ${ }^{1}$, \\ Ron Van Der Wal ${ }^{1}$ and Piet Verbiest ${ }^{1}$
}

\section{${ }^{*}$ Correspondence:}

o.lemmers@cbs.n

${ }^{1}$ Statistics Netherlands, The Hague, Heerlen, Bonaire, The Netherlands

Full list of author information is available at the end of the article

\begin{abstract}
Firm size is increasingly acknowledged as an important factor for (macro-)economic policy. It is known that the overall importance of small- and medium-sized enterprises (SMEs) is different relative to large multinationals in terms of their impact on economic growth, exports and innovation. Yet empirical evidence to substantiate the role of firms of different sizes is rare. To tackle this problem, we develop a novel approach by extending the Dutch supply-use framework to firm size. We utilize firm-level data to construct a purpose-built supply-use table distinguishing between SMEs and large enterprises and derive an extended input-output table. In doing so, we adopt a more evolved definition of SMEs, accounting for the fact that small firms may be subsidiaries of large (multinational) enterprise groups. The analysis shows that due to their function as suppliers, SMEs benefit much more from Dutch exports to foreign markets than the traditional export figures show. SMEs are less dependent on imports than large enterprises. This might be detrimental to the competitiveness of SMEs if they do not fully appreciate the benefits of sourcing internationally in terms of cheaper or higher quality inputs. The paper shows the policy relevance of macroeconomic statistics which distinguish firm size.
\end{abstract}

Keywords: Exports, SME, GDP supply-use tables, Input-output table, Input-output analysis, Firm heterogeneity

\section{Introduction}

It is well known (Bernard et al. 2007, 2012) that SMEs are trading less on international markets compared to larger firms. This can lead to disadvantages for SMEs, since they might miss out on growth opportunities that foreign markets provide. Therefore, many countries have specific policy instruments in place to stimulate SMEs to overcome perceived barriers and internationalize their business activities through exporting or investing abroad. ${ }^{1}$ However, in order to be able to develop effective policies, it is crucial to gain a proper understanding of the position of SMEs in global value chains, since SMEs might still profit from exports indirectly if they act as a supplier to larger enterprises.

\footnotetext{
${ }^{1}$ Wymenga et al. (2013) investigated the number of support services in EU countries and 25 other countries for EU SMEs in international business and found 1542 different support services offered by 1197 organizations, varying from business associations, chambers of commerce, governmental institutions to trade and investment agencies.
} 
Policy makers appreciate novel insights on the role of SMEs and large enterprises in the economy to build on in the policymaking process. For example, how do SMEs contribute to the economy, mainly as suppliers to final users or mainly by supplying to other industries? Are there important differences across industries? Are SMEs less dependent on international markets compared to large enterprises when the value chain is taken into account? To what extent do the input structures of SMEs and large enterprises differ?

The usual approach to this type of questions would be an analysis using an industry $\mathrm{x}$ industry input-output table, but that does not work here. A key assumption underlying input-output tables and the analyses derived from them is that of homogeneous industries (Miller and Blair 2009). One of the consequences is that all enterprises operating within the same industry are assumed to use the same proportion of imported goods and services for their productive process. So irrespective of firm size, the technological and market position of firms is assumed to be the same within industries.

However, enterprise homogeneity within industries does not hold in practice. ${ }^{2} \mathrm{Sev}$ eral dimensions of enterprise heterogeneity have been investigated empirically, and their correlation with enterprise performance measures such as innovation, profitability and productivity has been widely tested [see, for instance, Wagner $(2007,2012)$ and Bernard et al. $(2007,2012)$ for reviews of this literature]. Neglecting important sources of heterogeneity in input-output analysis might introduce a bias in estimates of integration of a country in global value chains, since the enterprises that export are, for example, known to use relatively more imports (Piacentini and Fortanier 2015). ${ }^{3}$

Given the importance of firm size, ownership and other firm properties as a source of heterogeneity, the Organisation for Economic Co-operation and Development (OECD) has initiated the OECD Expert Group on Extended Supply and Use Tables (OECD 2014) in which about 15 institutions share their experiences with accommodating firm heterogeneity in supply and use tables. In this paper, we adopt the suggestions of the OECD Expert Group. First, we describe the construction of an extended supply and use table (SUT) and input-output table (IOT) for the Netherlands which distinguishes firm size. Then, we summarize its key properties and discuss some analytical findings resulting from our empirical analysis.

The novelty of our paper is twofold. First, while a few earlier studies (such as USITC 2010; Piacentini and Fortanier 2015; Statistics Denmark and OECD 2017, see also Sect. 2) have split input-output tables according to firm size (frequently using aggregate data), we are, to the best of our knowledge, among the very first to derive a supply and use table from the micro-data accommodating firm size and compile an input-output table from this purpose-built SUT. This elaborate micro-data-driven procedure enables the construction of an IOT of considerably higher quality and detail. The construction is explained in detail so that others can replicate it completely or partially, depending on data availability. Second, we adopt a more evolved definition of SMEs in our analysis.

\footnotetext{
2 The level of heterogeneity is of course also dependent on the level of aggregation of industries in the input-output table. An input-output table with ten industries is far more heterogeneous than the US or Japanese tables which distinguish over 500 industries.

${ }^{3}$ Note, however, that a split by size class does not resolve all heterogeneity problems in the input-output table, since additional differences between exporters and non-exporters, multinationals and non-multinationals and so on remain (Statistics Denmark and OECD 2017).
} 
The "traditional" statistical delineation of SMEs entails nothing more than a division between enterprises with less than 250 employees and enterprises with 250 or more employees. ${ }^{4}$ For this paper, we have adopted a definition which specifies that enterprises should jointly, at the highest national aggregate level (the enterprise group ${ }^{5}$ ), have less than 250 employees and should not be a subsidiary of a foreign multinational enterprise. This definition is much closer to the EU definition of SMEs (European Commission 2018), which is used to establish if an enterprise is eligible for SME support funds. In addition, it yields a much clearer picture of the population of firms that is generally perceived to be "true" SMEs, excluding, for example, subsidiaries of large multinational enterprises.

The rest of this paper is organized as follows. Section 2 provides a brief discussion of the relevant literature. Section 3 details the delineation of SMEs, the procedure of splitting the supply-use table, the procedure of constructing the input-output table and how this was implemented in practice. Our results are discussed in Sect. 4, whereas Sect. 5 concludes. "Appendix" discusses the finer details of the methodology.

\section{Literature}

Abundant empirical studies have shown that international fragmentation of production has been rapidly increasing over the past decades. Hummels et al. (1998) and Hummels et al. (2001) coined the term vertical specialization in this respect, measured as the imported content of exports, and showed that vertical specialization has increased by about $40 \%$ in the period 1970-1995. Developing a longer time series, Johnson and Noguera (2012) corroborate this notion by showing that the average ratio of value added embodied in exports to exports itself has fallen by 10-15 percentage points in total in the period 1970-2009, although considerable cross-country heterogeneity exists. This narrative is also confirmed by Timmer et al. (2014) and Baldwin (2016) in more recent contributions.

The rise of global value chains (GVCs) has caught the attention of policymakers, because the integration of firms in GVCs provides opportunities for economic growth. There is some empirical evidence in this respect, suggesting that an increasing degree of integration in GVCs at the industry level is associated with increased productivity and domestic value added (Kummritz 2016). In addition, GVCs also provide a platform for the diffusion of innovation, technologies and ideas (Dietzenbacher and Los 2002).

SMEs employ a large part of the workforce, generate a large part of value added, but are less well connected to international markets than larger enterprises (Statistics Denmark and OECD 2017). ${ }^{6}$ Van den Berg (2014) shows that the fraction of non-trading

\footnotetext{
$\overline{{ }^{4} \text { See http://ec.europa.eu/eurostat/statistics-explained/index.php?title=Glossary:Small_and_medium-sized_enterprise }}$ s_(SMEs).

${ }^{5}$ An enterprise group is an association of enterprises bound together by legal and/or financial links. A group of enterprises can have more than one decision-making center, especially for policy on production, sales and profit. It may centralize certain aspects of financial management and taxation. It constitutes an economic entity which is empowered to make choices, particularly concerning the units which it comprises.

${ }^{6}$ Besides size, foreign ownership is positively correlated with trading activity as well. Illustrative in this respect is the descriptive finding of De Bontridder - De Steur et al. (2015) that foreign-owned enterprises in the Netherlands make up just over $1 \%$ of the business population, but in the trade in goods statistics account for more than half of Dutch imports and over $40 \%$ of Dutch exports. This includes re-exports but excludes quasi-transit trade. In the data and in the analysis, we will treat foreign-owned enterprises as large enterprises, since they can benefit from the advantages that the parent enterprise abroad provides, such as access to an international network or easier access to finance.
} 
enterprises in the Netherlands is $85 \%$ among the smallest enterprises but is less than $30 \%$ among large enterprises. Piacentini and Fortanier (2015) find that this is the case for most OECD countries. However, non-trading firms can still be dependent on global value chains indirectly, by serving as a supplier to (large) domestic multinational enterprises (MNEs) that are well integrated in GVCs.

Surprisingly little research is available about the extent to which domestically oriented firms indirectly depend on GVCs. Beverelli et al. (2016) note that GVCs are generally set up by large MNEs. They show empirically that strong domestic links across industries (domestic fragmentation) explain subsequent deep integration in GVCs. This could imply that a considerable part of firms is indirectly dependent on developments on foreign markets while not exporting themselves. This notion is corroborated by findings of Bernard et al. (2015) derived from a sample of Japanese firms and their domestic production networks. They show that large firms have more suppliers than small firms and, more importantly, that the better connected the firm, the less well connected its suppliers and vice versa. Although their analysis only concerns domestic production networks, it seems intuitive to extrapolate their findings to a model in which large numbers of smaller firms with small networks serve as a supplier to a relatively small number of larger MNEs well integrated in GVCs.

Methods to split IO-tables have been developed in several earlier papers. Pommée and Van Dalen (1997) use enterprise information to split the Dutch SUT of 1992. Subsequently, they derive an extended IO-table where industries are split into three size classes. USITC (2010) divided the IO-table of the USA for 2007 into SME- and large enterprise-specific accounts using an enterprise size-specific disaggregation of indicators such as exports in each industry. The estimates show that SMEs account for $41 \%$ of the total domestic value added that is embodied in exports of the USA, even though their share in direct exports is only $28 \%$. Using a similar methodology, Piacentini and Fortanier (2015) show that SMEs in European countries generally have a much larger share in the value added that is embodied in exports than in direct exports. Tang et al. (2016) show that in China state-owned enterprises and SMEs have much higher value added embodied in exports to direct exports ratios, compared to the rest of the economy. Note that these studies only consider the size of an enterprise to delineate SMEs and other enterprises. As explained in Introduction, we use a different definition. Our definition considers the size of the corresponding enterprise group and whether the enterprise is foreign owned or not.

Other dimensions of firm heterogeneity have also been accommodated in the IOframework. Yang et al. (2015) found that splitting the Chinese input-output table into processing and non-processing industries leads to very different estimates of vertical specialization. Co-operation between the statistical institution of the Nordic countries and the OECD (2017) showed among others that the differences between foreign- and domestically owned enterprises also translate to their direct exports and value added embodied in exports. This study also found that on average foreign-owned enterprises depend more on imports to produce. Hence, their exports contain less domestic value added.

Disaggregating IO-tables along the industry dimensions could also tackle the heterogeneity issue. However, the OECD expert group on extended SUTs (OECD 2014) 
anticipates that the optimal strategy varies even by country, since there is considerable country-level heterogeneity. As a case in point, China and Mexico have relatively large processing industries, which is why the multi-region input-output table of the OECD splits many industries of these countries into processing and non-processing industries (OECD 2015). Disaggregating IO-tables along other than industry dimensions has the advantage that it will yield new policy-relevant insights depending on the type of heterogeneity (size class, ownership, processing yes/no and so on) that is considered.

Our paper derives an extended IO-table, but contrary to the examples described above it does this by creating an extended SUT first. This has additional advantages. Namely, balancing can take place on a far more detailed product by industry classification level. Furthermore, it avoids unlikely product $\times$ size class combinations and allows for a nonproportional distribution over the size classes of items that are difficult to capture with regular statistics such as fraud and other forms of undeclared income.

\section{Methods}

\subsection{General description of methodological process}

First, we constructed an extended supply-use table from which subsequently an extended input-output table was derived. This was done for the year 2012 (if data from a different year are used in the construction, this is explicitly stated). The choice for 2012 was made because at the time of construction this was the most recent year for which the maximum level of detail is incorporated in the Dutch national accounts.

The methodology used to construct the extended SUT and IOT is similar to the procedure used to construct the regular SUT and IOT for the Dutch economy. See Eurostat (2008) for a description of the general methodology to derive SUT and IOT, Eurostat (2013) for a description of the methodology of national accounts itself and Statistics Netherlands (2017) for the details of the implementation in the Netherlands. Whereas a traditional SUT combines information from different sources to obtain data on production, value added, intermediate consumption and final consumption at the industry level, our extended SUT adds the size dimension, resulting in disaggregation at the industry size class level. The process of constructing the extended SUT and IOT consists of the following steps.

1. Define size classes and resulting industry size class clusters. In the construction of the extended SUT, we will distinguish between five size classes. We combine these size classes with the industry classification that is used in the regular national accounts process, 128 industries based on ISIC (international standard industry classification) Rev. 4, to obtain industry size class clusters. Overall, there are 640 potential industry size class combinations (128 industries times five size classes).

2. Assign production, intermediate consumption and value added to each industry size class cluster. Key in the construction of the extended SUT is the availability of data on production, value added and intermediate and final consumption in each industry size class cluster. Depending on the data sources that are available for a cluster, different estimation procedures are followed and assumptions are made to construct the corresponding parts of the extended SUT. 
3. Populate the SUT-system with estimates produced in the first two steps and balance. The result is an extended SUT.

4. Split exports from domestic origin into industry size class clusters. Split intermediate use of imports into industry size class clusters as well. This step requires micro-level data on imports and exports of goods and services.

5. Use the extended SUT obtained in step 3 and the information from step 4 to derive the extended IOT. First, for each commodity, an IOT is constructed from the extended SUT assuming a fixed sales structure. All commodity-specific IOTs are then aggregated to derive the extended IOT.

We will discuss each of these steps in turn, although we will frequently refer to "Appendix" for more detail. In these steps, we will use the following data for the year 2012:

- The existing SUT

- Microdata from the General Business Register

- Microdata about foreign ownership of an enterprise

- Microdata from the Structural Business Statistics survey

- Microdata from the PRODCOM survey

- Microdata about imports and exports of goods

- Microdata about imports and exports of services

The microdata are always on enterprise level. Microdata from the PRODCOM survey (where enterprises in manufacturing report their production on product level) and microdata about trade in goods are on enterprise $\times$ product level.

\subsection{Defining enterprises, size classes and industry size class clusters}

An enterprise bundles a coherent set of business activities leading to the production of a set of goods and services and may consist of more than one legal entity. ${ }^{7}$ A domestic enterprise group on the other hand may consist of one enterprise (the majority of cases), or it may group multiple enterprises producing different goods and services.

In order to assign enterprises to a particular industry and size class (in terms of labor), we rely on information available in the General Business Register (GBR). The GBR contains detailed information on all active enterprises in a particular year, including unique enterprise identifiers, their main industry of activity and the number of persons employed by the enterprise and the enterprise group. The General Business Register is the backbone of all business statistics in the Netherlands. From the Foreign Affiliates Statistics, it is known whether the enterprise is part of a domestic enterprise group or whether the enterprise is foreign owned.

The traditional delineation of SMEs is done at the level of the enterprise. Small enterprises employ less than 50 employees, and medium-sized enterprises employ between 50 and 250 employees. However, this implies that under this definition small enterprises that are part of a larger (national or international) enterprise group are also considered

\footnotetext{
${ }^{7}$ Consider a manufacturer of basic metals and the seller of these basic metals both owned by the same family but organized as two legal entities active in the Netherlands. Since both legal entities operate in the basic metals industry, they are considered one enterprise.
} 


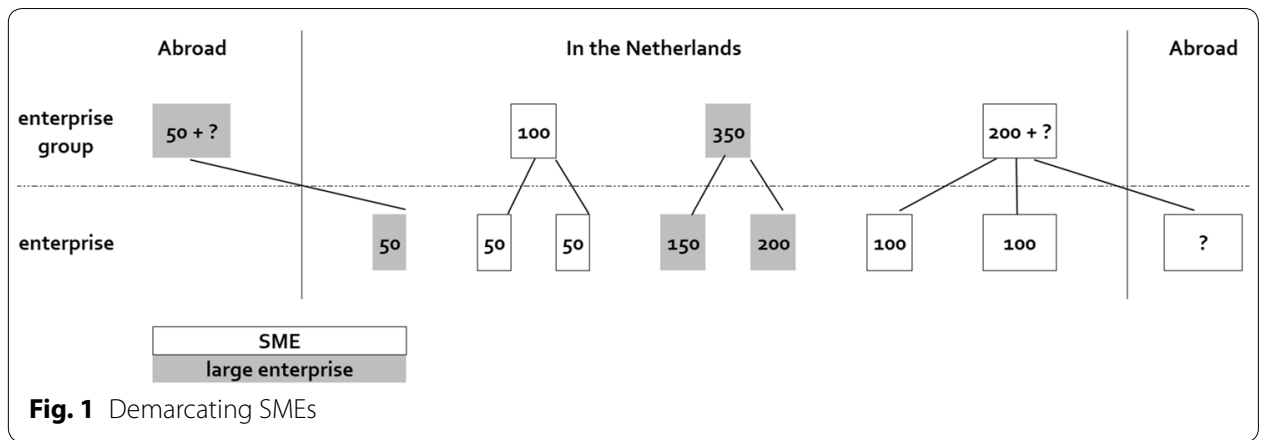

SMEs. Consider a distribution center of a large foreign car manufacturer employing 50 people locally, but employing thousands worldwide. From a policy perspective considering this enterprise as an SME is less desirable, since policies specifically targeting SMEs are generally not developed with this type of enterprise in mind. To mitigate this issue, we rely on a modified version of the SME definition proposed by the EU (European Commission 2018) in the context of SME policy design and evaluation. ${ }^{8}$

This modified definition delineates SMEs using two dimensions of the (domestic) enterprise group: size and nationality of ownership. This is explained in Fig. 1. Enterprises should jointly, at the highest national aggregate level (the enterprise group), have less than 250 employees to be considered an SME. In addition, enterprises of which the ultimate controlling institution is located outside the Netherlands are always considered to be part of a large multinational enterprise (MNE). In an empirical assessment of the various delineations of SMEs, Lemmers (2014) shows that in terms of trade the impact of applying the modified EU definition of SMEs relative to the traditional definition of SMEs is large. For example, the value of imports and exports that is assigned to SMEs is more than halved when the stricter modified EU definition is applied.

A few decisions we make in this process need clarification. First, enterprises under foreign control (multinational enterprises or MNEs) could jointly, at the international aggregate level of the parent company, still have less than 250 employees and thus in a strictly technical sense be an SME. Second, domestically owned enterprise groups with less than 250 employees in the Netherlands could have subsidiary companies abroad rendering the international conglomerate too large to be considered an SME. This is discussed in "Appendix."

Based on the GBR data and following the delineation of an SME defined above, all 1.4 million enterprises in the GBR are assigned to a particular industry size class cluster. Namely, enterprises are assigned to a particular industry using the main industry of activity of the enterprise as listed in the GBR. At the most detailed level, the extended SUT and IOT distinguish 128 industries. We distinguish five size classes:

1. Small enterprises employing at most 50 employees, not part of a large domestic enterprise group and not foreign owned;

\footnotetext{
${ }^{8}$ In the operationalization of this definition, the criterion concerning the combination of turnover and balance sheet total is excluded due to data limitations. Moreover, we rely on domestic enterprise group size as a proxy for global group size which we do not observe.
} 
2. Medium-sized enterprises employing between 50 and 250 employees, not part of a large domestic enterprise group and not foreign owned;

3. Small- or medium-sized enterprises that are linked to large domestic enterprise groups and/or are foreign owned ${ }^{9}$;

4. Large enterprises employing more than 250 employees;

5. Unassigned enterprises: Enterprises active in financial services, government services, education or healthcare are not assigned to a particular size class.

Overall, there are 640 possible industry size class combinations (128 times 5) at the most detailed level. But since an industry is split into categories 1-4 or not split at all (category 5), fewer industry size class combinations remain, a total of 459.

\subsection{Assigning production, intermediate consumption and value added to each industry size class cluster}

The process of constructing the extended SUT is largely similar to the process of constructing the conventional (containing no enterprise characteristics except the industry) supply-use table (SUT). The biggest difference lies in the use of the industry size class clusters defined in the previous step. To construct the extended SUT, we require information on production, intermediate consumption and value added at the industry size class cluster level. Depending on the data available, we adopt different methods to obtain information for each of the industry size class combinations that occur in practice. We will discuss the different methods in turn.

The primary data source used to obtain information on production, intermediate consumption and value added is the Structural Business Statistics (SBS) survey. The SBS contains financial information for a selection of industries referred to as the "non-financial business economy."10 The SBS survey is exhaustive for enterprises employing more than 50 employees, and for smaller enterprises, a combination of tax data and a survey based on random sampling is used to obtain data in each industry size class cluster. ${ }^{11}$ The response in the SBS survey for turnover is about $80-90 \%$ (depending on the industry) of the total estimated turnover. We then calculate total value added by industry size class cluster. See "Appendix" for more details.

Next, we tackle industries that are not covered by the SBS. This concerns the industries agriculture, forestry and fishing, financial institutions, government, education, healthcare and culture, sports and recreation. Except for the financial institutions, these industries have limited exports. Several industries will not be split either because of lacking information (e.g., financial institutions) or because it is moot (e.g., government); others will be split using information from outside the SBS. See "Appendix" for more details.

\footnotetext{
9 This allows constructing information employing the "traditional" definition of SMEs as well.

10 Industries covered by the SBS are agricultural services, mining and quarrying, industry, electricity, gas and water supply, waste management, construction, wholesale and retail trade, transportation and storage, accommodation and food services, information and communication services, business services and personal services. In ISIC 4, this corresponds to B-N minus K.

11 It should be noted that the industry size class clusters of the SBS do not always match perfectly with the industry size class clusters defined in Sect. 3.2. In 77 out of 1068 size class industry combinations (size class of the SBS), this discrepancy leads to missing data for a particular industry size class combination required for the extended SUT, since the population registry contains enterprises in a particular size class industry combination, but no response is recorded for the SBS. In these cases, the necessary information is imputed using data from adjacent size class industries.
} 
Finally, in order to construct a complete picture of the economy, the economic value corresponding to some activities is being estimated and imputed as far as they are either incompletely observed or not observed at all. Note that several of these adjustments are not specific to the added size class dimension. Also, some adjustments have to be made because the SBS and national accounts use different concepts. All of the additions and adjustments are also part of the regular SUT procedure. See "Appendix" for more details.

The resulting estimates per industry size class cluster are reconciled with published national accounts data for total output and total intermediate consumption. Subsequently, product data are reconciled with the aforementioned totals.

In a final step, the supply-use table including size class dimension is balanced by applying the same algorithm as for constructing the regular supply-use table. In this process, expert knowledge plays a crucial role. The outcome of the balancing procedure is evaluated on its plausibility, e.g., by investigating ratios such as the production per worker and the likeliness that certain industry size class clusters perform certain activities (e.g., it is unlikely that small enterprises build complete ships). This process ultimately yields a supply-use table with a size class dimension that is fully consistent with the SUT reported in the National Accounts for 2012. However, supply and use are not yet divided in a domestic and foreign part. This takes place in the next step.

\subsection{Accounting for differences in supply and demand structure between industry size class clusters using trade data}

For the transformation of the SUT to an IO-framework, it is necessary to split supply and use into domestic and foreign parts. This accounts for differences in the supply and use structure of different industry size class clusters. Specifically, we employ micro-level data on trade in goods and services to separate domestic demand from exports and domestic supply from imports in each industry size class cluster.

The international trade in goods (ITG) data contain detailed information on the enterprise importing or exporting and (with exception of the smaller traders) ${ }^{12}$ the products traded. This is necessary to accommodate an important methodological difference between ITG and national accounts: In ITG, trade is assigned to the trading enterprise, whereas for national account purposes, exports (imports) by intermediaries (wholesalers, transport companies) are re-assigned to the producing (consuming) industries by exploiting the product dimension of the trade data. Details can be found in "Appendix."

The compilation of data concerning trade in services by industry size class cluster is somewhat different. First, the trade in services data by industry size class cluster have been prepared for the year 2014, because several methodological improvements have been implemented in 2014 compared to earlier years. The trade values for 2014 have been extrapolated back to 2012 using commodity-level value growth figures, assuming the same growth for each industry size class. Furthermore, the treatment of travel differs between imports (Dutch residents traveling abroad) and exports (foreigners traveling to the Netherlands). See "Appendix" for more details on both matters.

\footnotetext{
${ }^{12}$ For extra-EU trade, data on the products traded and origin and destination are always available. For intra-EU trade, a reporting threshold of 900,000 euro applied in 2012. Enterprises that export (import) less than this cutoff value do not have to report a breakdown of their exports (imports) at the product and destination level.
} 
Table 1 Detail of SUT and IOT

\begin{tabular}{lcc}
\hline & Unpublished tables & $\begin{array}{l}\text { Published } \\
\text { tables }\end{array}$ \\
\hline Split industries & 115 & 56 \\
Unsplit industries & 13 & 13 \\
Products & 650 & 78 \\
Primary inputs & 16 & 12 \\
Categories of final demand & 18 & 9 \\
\hline
\end{tabular}

\subsection{Deriving the extended input-output table}

Finally, the input-output table distinguishing between SMEs and large enterprises is derived from the SUT by adopting the same method that is used to derive the regular IOT. That means that a separate IOT is constructed for each commodity in the SUT. The row and column totals of this commodity-specific IOT are filled using the commodity-specific supply and use table. Domestic demand can then be calculated as the remainder of production minus exports and can be disaggregated into intermediate and final demand by assuming a fixed product sales structure (cf. method D in Eurostat 2008 to derive an IOT from an SUT) of size classes within industries. The final extended IOT is derived by adding all commodity-specific IOTs. The actual SUT and IOT (unpublished) contain 115 split industries and 13 unsplit industries (see Table 1 for more details).

The published tables (Chong et al. 2016a) contain less detail, namely 56 split industries and 13 unsplit industries. There are several reasons for publishing in less detail: firstly, the stability of the results. Already in the regular published tables, without a split by size class, industries are aggregated because in some cases the industry data are based on too few observations. We follow this aggregation in order to publish at the same industry level as the regular tables. Secondly, we aggregate a little more because of confidentiality. In some cases, the number of enterprises in an industry size class cluster was low and it would be possible to derive the results of a single enterprise. This is not allowed under Dutch statistical law. To preserve confidentiality, two methods were used. Either two industries would be aggregated to one (e.g., manufacture of tobacco was combined with manufacture of beverages) or the industry would not be split by size class (e.g., mining, postal and courier services).

\subsection{Estimating the contribution of SMEs to value added}

After deriving the extended IOT, it is possible to estimate the contribution of SMEs to value added in exports and in domestic final demand. Our empirical method to do this derives from a basic input-output model (Miller and Blair 2009). For the purpose of the current extended IO-framework, it is useful to note that we have incorporated the industry and size class dimension in what would commonly be the industry dimension. As a consequence, the extended IO-table differs solely from its standard counterpart (industries only) in that it has more rows and columns. Hence, we can rely on a basic input-output model to illustrate our empirical method, which aims to 
calculate the contribution of SMEs and large enterprises to total value added. A similar analytical framework has been applied in many different empirical settings; see, for instance, Su et al. (2010). See "Appendix" for details.

All necessary information for the input-output analysis is derived from the extended input-output table of 2012 separating between 128 industries and five size classes (small, medium-sized, small- and medium-sized subsidiaries of large enterprises and/ or foreign-owned enterprises, large and undivided). Although all analyses are carried out at the lowest level of aggregation possible (128 industries $\times 5$ size classes), we will not report results at this level for confidentiality considerations.

\section{Results}

This section illustrates the different roles of SMEs and large enterprises in the Dutch economy. First, it shows the distribution of the value added generated by SMEs and large enterprises over industries. Then, we present results of several basic input-output analyses obtained by using the newly developed extended IOT. Besides estimating the imports embodied in exports, this table also shows the roles of the two size classes as suppliers to intermediate and final demand, and their involvement in (the Dutch part of) global value chains. In this section, an enterprise is considered to be an SME if its enterprise group is under Dutch control and has less than 250 persons employed.

\subsection{Contribution of SMEs to the Dutch economy: industry differences}

Although the total value added by SMEs is comparable to the total value added by large enterprises, Table 2 shows that there are large differences between the distributions of value added over industries. SMEs are relatively large in terms of value added in agriculture, construction, trade and services. Mining and manufacturing are dominated by large enterprises which therefore dominate the value added of these industries. This is an intuitively straightforward finding; a farmer or wholesaler can easily be operational with less than 250 employees, whereas the petrochemical industry, for example, is comprised almost exclusively of large enterprises.

Obviously, the differing distributions of SMEs and large enterprises by industry will affect indicators at the macroeconomic level. As a consequence, we need to be careful with the interpretation of observed differences between SMEs and large enterprises, because they might stem from a composition effect (with SMEs being overrepresented in particular industries and underrepresented in others) rather than operational differences between SMEs and large firms. Throughout this section, we will look into this issue by means of several Wilcoxon signed-rank tests at the industry level. This nonparametric test is used when comparing two related samples, in this case the two size classes. Due to confidentiality issues (see paragraph 3.6), the results of these tests are not reported at the most detailed level of aggregation (which distinguishes 128 industries) but on a more aggregated level (distinguishing 69 industries). Industries that are not split, such as financial institutions, are not included in the graphs and the statistical tests. Industries for which we assume that the input-output structure is the same for each size class (due to lack of information from the SBS, see paragraph 3.3), such as culture, sports and recreation, are not included either. If the difference between SMEs and large enterprises 
Table 2 Distribution of value added over industries, by size class, 2012

\begin{tabular}{|c|c|c|c|c|c|c|}
\hline & \multicolumn{2}{|l|}{ SME } & \multicolumn{2}{|c|}{ Large enterprises } & \multicolumn{2}{|l|}{ Unsplit } \\
\hline & $\begin{array}{l}\text { Value } \\
\text { mln euro }\end{array}$ & $\begin{array}{l}\text { Share in total } \\
\%\end{array}$ & $\begin{array}{l}\text { Value } \\
\text { mln euro }\end{array}$ & $\begin{array}{l}\text { Share in total } \\
\%\end{array}$ & $\begin{array}{l}\text { Value } \\
\text { mln euro }\end{array}$ & $\begin{array}{l}\text { Share in total } \\
\%\end{array}$ \\
\hline $\begin{array}{l}\text { Agriculture, forestry and } \\
\text { fishery }\end{array}$ & 9729 & 4.5 & 496 & 0.3 & 0 & 0.0 \\
\hline $\begin{array}{l}\text { Mining and quarrying, } \\
\text { manufacturing and } \\
\text { utilities }\end{array}$ & 32,188 & 14.9 & 69,268 & 36.6 & 0 & 0.0 \\
\hline Construction & 19,703 & 9.1 & 8123 & 4.3 & 0 & 0.0 \\
\hline $\begin{array}{l}\text { Trade, transport, accommo- } \\
\text { dation and food services }\end{array}$ & 65,022 & 30.1 & 50,119 & 26.5 & 0 & 0.0 \\
\hline Financial services & 0 & 0 & 0 & 0 & 49,908 & 28.0 \\
\hline Business services & 43,432 & 20.1 & 35,276 & 18.6 & 0 & 0.0 \\
\hline $\begin{array}{l}\text { Government, education } \\
\text { and health care }\end{array}$ & 0 & 0 & 0 & 0 & 128,584 & 72.0 \\
\hline Other services & 45,925 & 21.3 & 26,068 & 13.8 & 0 & 0.0 \\
\hline Total & 215,999 & 100 & 189,350 & 100 & 178,492 & 100.0 \\
\hline
\end{tabular}

Table 3 Composition of the input used in final production, by size class, 2012

\begin{tabular}{lcc}
\hline & SMEs & $\begin{array}{c}\text { Large } \\
\text { enterprises }\end{array}$ \\
\hline Own (direct) VA & $\%$ & 32 \\
Indirect VA of large enterprises & 41 & 10 \\
Indirect VA of SMEs & 11 & 13 \\
Indirect VA of unsplit industries & 16 & 2 \\
Imports & 11 & 41 \\
Other primary inputs & 19 & 1 \\
Total & 2 & 100 \\
\hline
\end{tabular}

is lower than 1 percentage point, we do not include the industry in the statistical test because the difference might be caused by rounding in the IO-table.

\subsection{Different composition of inputs for SMEs and large enterprises}

Besides differences between SMEs and large enterprises in terms of the industries, there are also differences in input structure. Based on our calculations, Table 3 shows that SMEs are less dependent on imports in the production of goods and services for final demand than large enterprises.

Other primary inputs in Table 3 are the sum of taxes less subsidies on imports, nondeductible VAT (value-added tax) and other taxes less subsidies on products. On average, SMEs need 19 cents of imports to produce 1 euro of final demand, whereas large enterprises need 41 cents. This lower import dependence can be observed in the majority of industries, as can be seen in Fig. 2.

A Wilcoxon signed-rank test indicated that the imports embodied in 1 euro final production are statistically significantly lower for SMEs than for large enterprises, $n=44, Z=-2.707, p<0.007$. As a consequence, the production for final demand by 


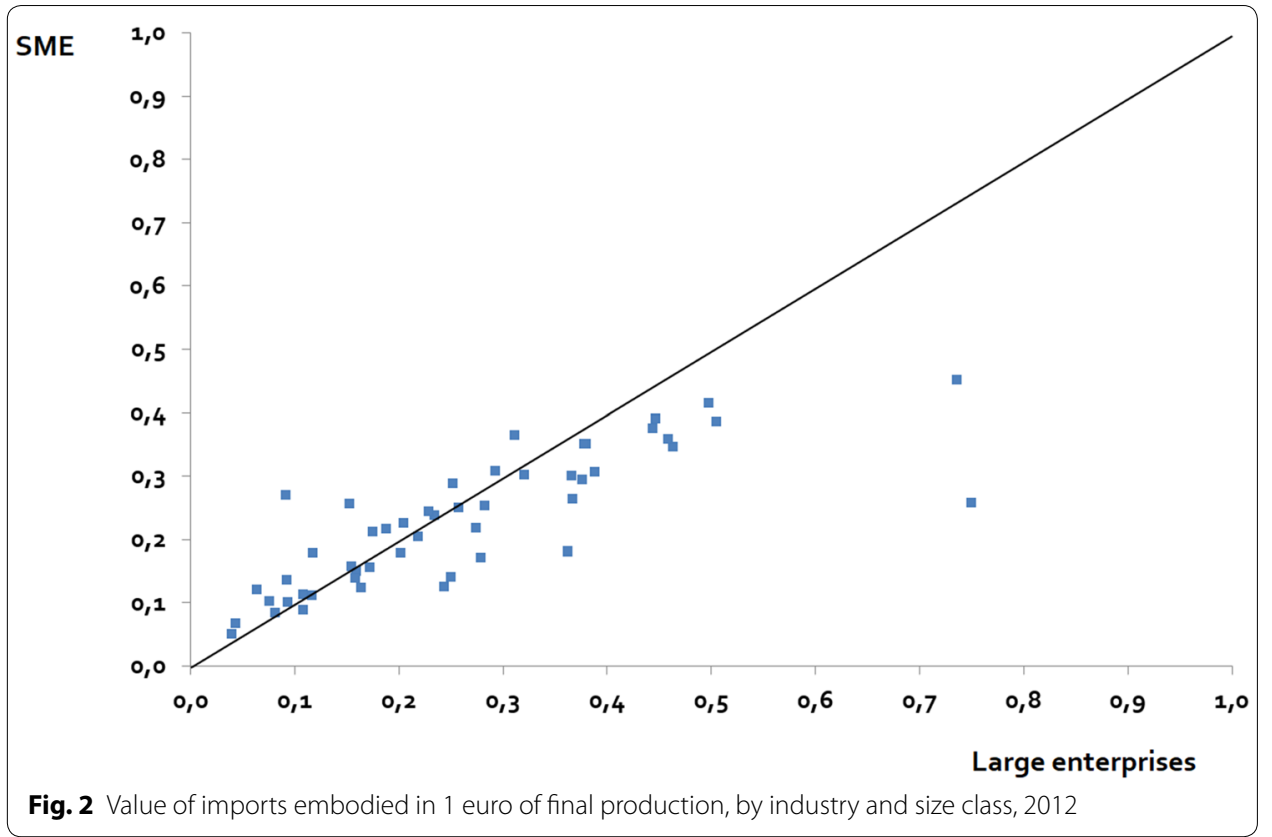

SMEs contains more Dutch value added per euro than that of large enterprises. Still, due to the scale of the large enterprises, their total value added is of the same magnitude as that of SMEs (as could be seen in Table 2). Table 3 also shows that of each euro of production by an SME for final demand, on average 41 cents of value added is generated by the producing SME. This is 32 cents for large enterprises. One might expect that SMEs rely less frequently on specialized suppliers of goods and services and that they carry out more of the necessary activities themselves before arriving at the final product. In other words, that there is less specialization in tasks among SMEs. However, this is not confirmed by our results; Fig. 3 shows that on industry level it varies: Sometimes, it is the SMEs, sometimes the large enterprises, with the highest own value added embodied in final production.

And a Wilcoxon signed-rank test between SMEs and large enterprises showed that the null hypothesis that these shares are equal cannot be rejected ( $n=45, Z=-0.006$, $p<0.995)$. This suggests that the findings on macro-level are caused by the different distribution of SMEs and large enterprises over the industrial landscape.

\subsection{Roles of SMEs and large enterprises in the Dutch economy}

There are notable differences between the roles of SMEs and large enterprises, as can be seen in Table 4. This table shows the output structure of the two types of enterprises, divided in a direct (seller to final consumer) or an indirect role (as a supplier of intermediates to others) and in a domestic and foreign (exports) part. SMEs are in general more often suppliers to other enterprises than suppliers to final consumers; $58 \%$ of their value added is due to supplying to other enterprises. Large enterprises create half of their value added due to sales to final consumers and half due to supplying others. 


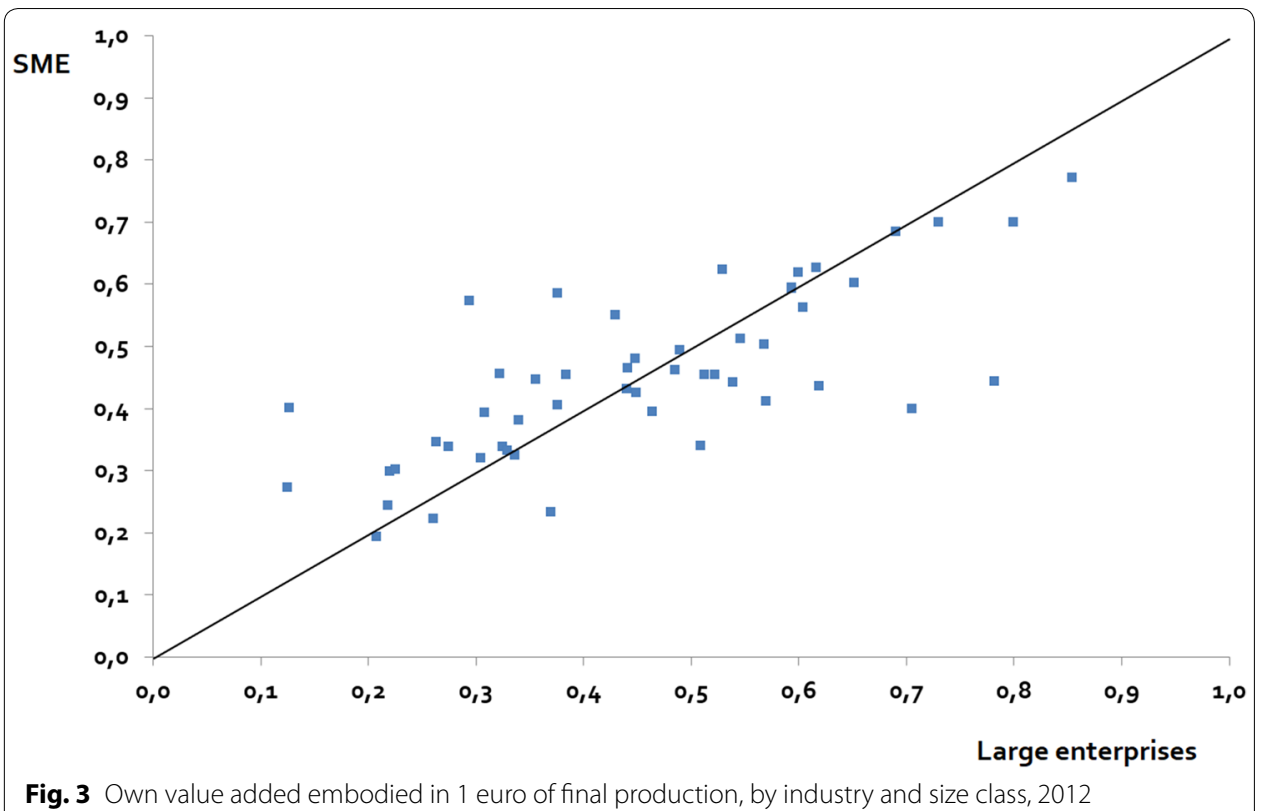

Table 4 Output structure of SMEs and large enterprises, 2012

\begin{tabular}{llc}
\hline & SMEs & $\begin{array}{l}\text { Large } \\
\text { enterprises }\end{array}$ \\
\hline Direct & \% of generated value added & \\
Domestic sales & 42 & 51 \\
Exports & 26 & 22 \\
Indirect, as a supplier & 16 & 29 \\
Domestic sales & 58 & 49 \\
Exports & 40 & 32 \\
Total & 18 & 17 \\
\hline
\end{tabular}

A Wilcoxon signed-rank test shows that SMEs have statistically significantly more indirect value added, as a supplier, than large enterprises $(n=46, Z=-4.037, p<0.000)$. This is illustrated by Fig. 4 and confirmed in other studies, e.g., the report of Statistics Denmark and OECD (2017) on the role of Nordic enterprises in global value chains.

\subsection{Exports of SMEs and large enterprises}

Another important conclusion that can be drawn from Table 4 is that SMEs generate more value added serving as a supplier in the value chain of an exporter than they generate by exporting themselves. Of their value added, $16 \%$ is due to direct exports and $18 \%$ due to indirect exports. But for large enterprises, the corresponding percentages are 29 and 17, respectively. In total, large enterprises derive more of their total value added from foreign markets, which is due to their direct exports.

It is not surprising that we observe that SMEs are less prone to international trade than large enterprises. Barriers that are often mentioned in the literature (e.g., Kneller 


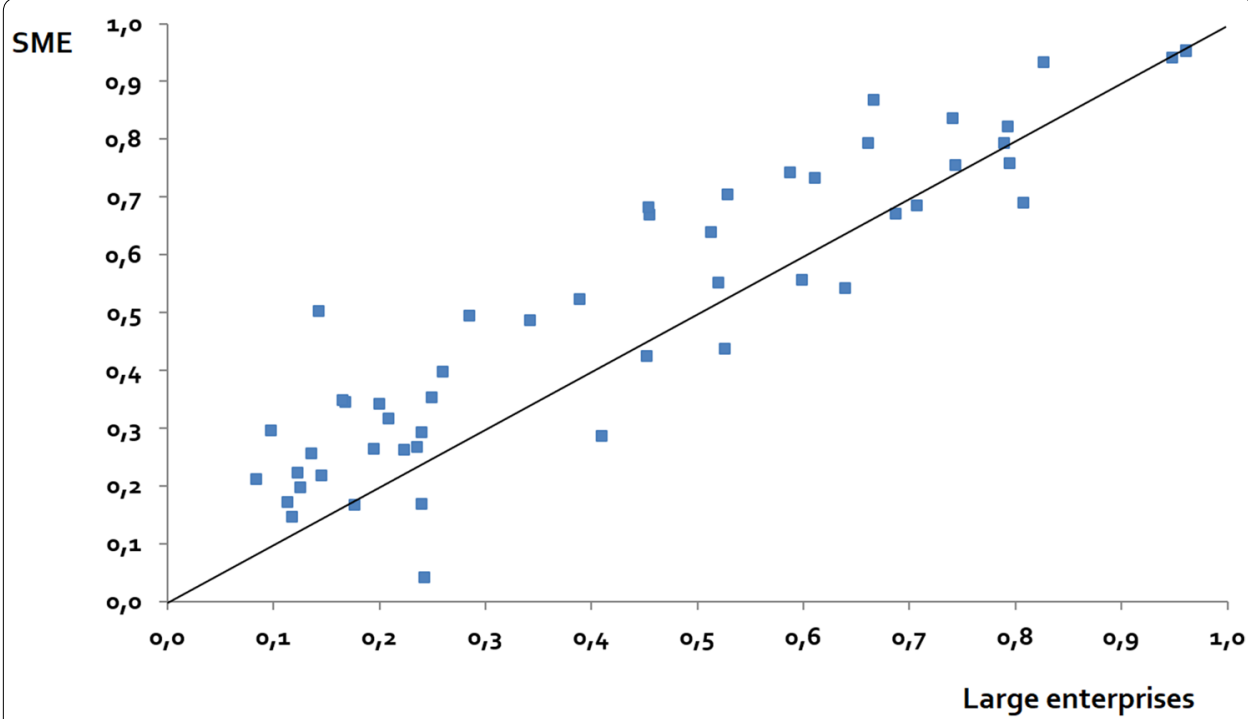

Fig. 4 Indirect value added as share of total value added, by industry and size class, 2012

and Pisu 2011; Smeets et al. 2010) by enterprises are obtaining information about foreign markets, finding business partners, dealing with cultural differences, complying with technical standards and regulations and political and economic conditions of foreign markets. The larger an enterprise, the easier it is to bear the fixed costs associated with overcoming such barriers (USITC 2014).

Barriers that obstruct SMEs to trade will obstruct them to import, thus creating an extra barrier to export as well. It has already been shown for the Netherlands (Van den Berg and Van Marrewijk 2017) that enterprises that import are more productive. In general, more productive enterprises enjoy larger export success [e.g., the surveys of Wagner $(2007,2012)]$, the rationale being that importing enables the enterprise to benefit from foreign input markets in terms of a larger variety of goods and services available at a lower price and/or with a higher quality. This enables the enterprise to be more efficient and productive than when they would have purchased similar inputs at the domestic market, which in turn makes enterprises more competitive on the international market.

With this narrative in mind, it should come as no surprise that SMEs are relatively more focussed on the domestic markets and relatively less on foreign markets. However, their customers on the domestic market generate considerable exports. As a consequence, SMEs have considerable indirect exports. Consequently, although SMEs might have a relatively small share in gross exports, they have a larger share in Dutch value added exports. This is shown in Fig. 5. For example, small enterprises account for 17\% of Dutch gross exports, but for $31 \%$ of Dutch value added that is due to foreign demand.

Figure 6 shows that this also holds for exports of domestically produced goods to each of the 12 most prominent trading partners of the Netherlands as well. Although SMEs are responsible for only $30 \%$ of the gross exports of goods to Germany, their share in the value added due to exports of goods to Germany is $50 \%$. About one-fifth of gross exports to China are carried out by SMEs, suggesting that they fall behind large enterprises in terms of not optimally taking opportunities that the high growth 

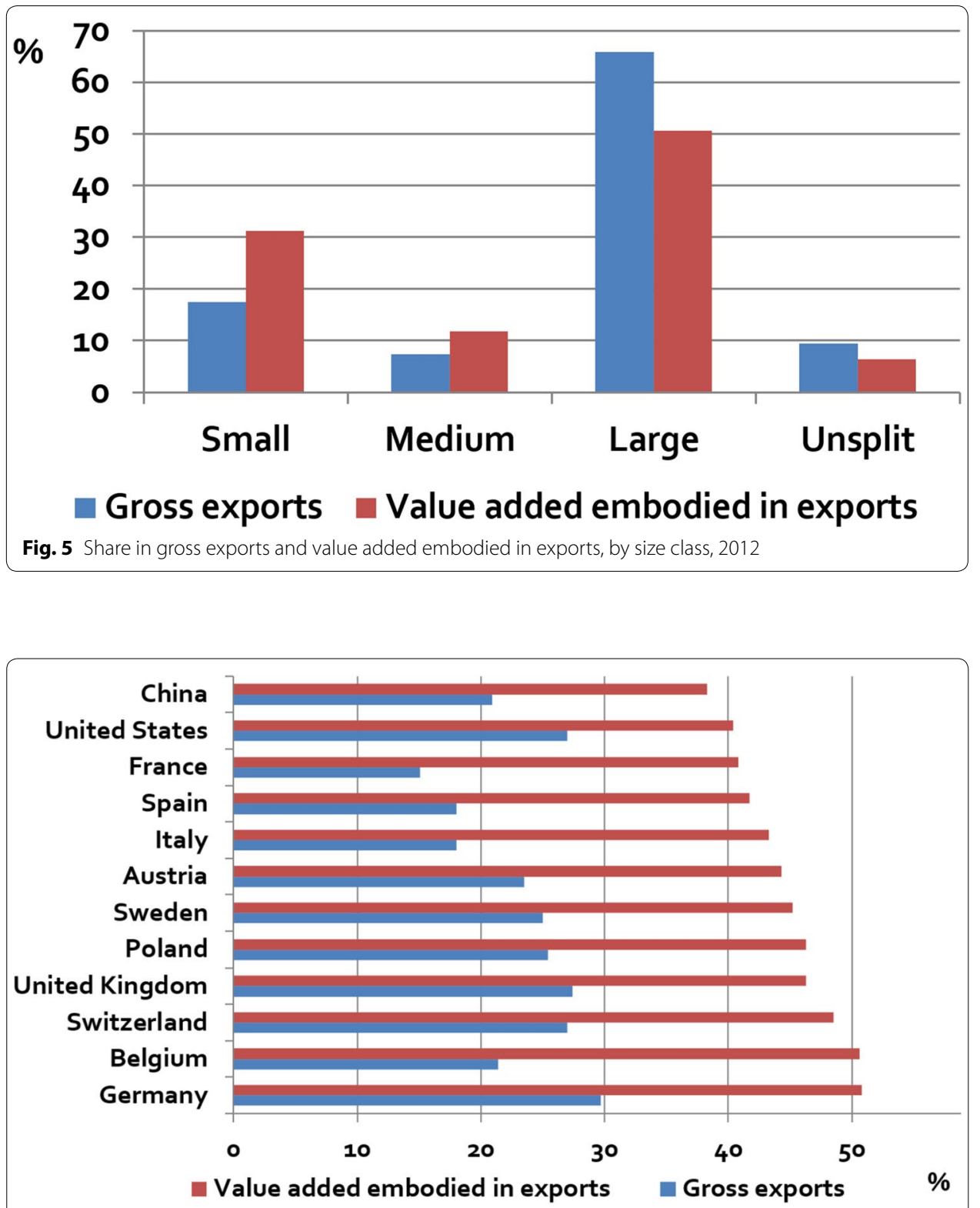

Fig. 6 Share of independent SMEs in Dutch produced exports to important partners, 2012

levels of the Chinese economy provide. Nonetheless, SMEs show to have a share of two-fifth in value added due to exports of goods to China by serving as a supplier in the value chains of exporters, twice as much as their share in gross exports.

A striking feature of Fig. 6 is the relatively large share of SMEs in gross exports to distant markets. Since exporting to more distant markets is supposedly more complex than exporting to nearby markets, one would expect that SMEs show a relatively small share in gross exports to markets such as China and the USA and mainly be active on those markets through indirect exports by serving as suppliers to large firms. However, the picture emerging from Fig. 6 seems to be the opposite; the ratio of the share in gross exports to the share in value added embodied in exports is higher 
at distant markets, particularly for the USA. It would be interesting to investigate what explains this phenomenon. It seems likely that it is a reflection of the fact that in the framework of the National Accounts exports by wholesalers are assigned to the producing industry. However, it could also be a dimension of the distance effect. Are larger destination economies such as China and the USA more interesting to SMEs than smaller markets nearby? This could be formally tested, for example in the setting of a simple gravity model of trade. Unfortunately, we do not have data on a sufficient number of destination countries to dig into this.

These findings are relevant to policymakers because there is concern (European Commission 2013) that SMEs might not benefit from trade expansion because their share in exports is relatively low. But their share in value added due to exports is often much higher than their share in gross exports, when taking the indirect exports into consideration. It is even a factor two for specific country partners. The consequence of this concealed form of internationalization is that SMEs will be hit harder by a significant drop in exports (such as in the 2008-2009 crisis), than is to be expected based on gross export figures. On the other hand, when exports increase, they will benefit more than expected.

\section{Conclusions}

Our disaggregation of industries into SMEs and large enterprises and the subsequent IO-analysis show that firms with different sizes play significantly differing roles in the Dutch economy. To arrive at these results, this paper extends the traditional supply-use (SUT) framework (and by extension the input-output (IOT) framework). Those tables have the industry as the only enterprise characteristic, whereas this paper also incorporates firm size (and foreign ownership). This enables us to account for, but not remove all, firm heterogeneity along these dimensions in our empirical analysis. We describe the process of constructing the extended SUT, present some key features of the resulting SUT and derive analytical findings from basic IO-analysis of the extended IOT, focusing on the question to what extent SMEs contribute to exports both directly and indirectly. This type of analysis leads to important new insights for policymakers.

The novelty of our paper is twofold. First, we are to the best of our knowledge among the very first to accommodate firm size in an IOT by deriving a supply and use table from the micro-data and compiling an input-output table from this purpose-built SUT. This elaborate micro-data-driven procedure enables the construction of an IOT of considerably higher quality and detail. The construction is explained in detail so that others can replicate it completely or partially, depending on data availability. Second, we adopt a more evolved definition of SMEs in our analysis that is much closer to the EU definition of SMEs (European Commission). This yields a much clearer picture of the population of firms that is generally perceived to be "true" SMEs, excluding, for example, subsidiaries of large multinational enterprises.

Using the resulting extended IOT reveals that the role of SMEs in the Dutch economy differs significantly from that of large enterprises, even though the value added generated by the two groups is comparable. The differing roles partially result from a composition effect in terms of industries. We observe that SMEs serve as suppliers to other enterprises more often than large enterprises that produce more for "final" products 
(sold directly to consumers and/or export). SMEs are more focussed on domestic markets for both their demand and supply of goods and services and less focussed on direct sales to foreign markets compared to large enterprises. Due to various barriers to international trade, SMEs are less active on international markets than large enterprises both in terms of imports and exports.

Using traditional measures of foreign market involvement (gross exports), SMEs seem to benefit relatively little from economic growth in foreign markets compared to large firms, because they are much less prone to export themselves: Their share in gross exports of domestically produced goods and services is only $25 \%$, whereas it is $66 \%$ for large enterprises (the remainder being exported by firms in unsplit industries). However, taking the complete value chain into account, a different picture emerges: The share of SMEs in Dutch value added due to exports is $43 \%$. This implies that SMEs depend much more on foreign markets than traditional "gross" trade figures show. SMEs serve an important role as suppliers to large exporting enterprises. By participating in such value chains, SMEs can benefit from the possibilities that foreign markets offer, without having to put up the considerable investment associated with exploring new export markets. The results thus suggest that large enterprises serve as a gateway to foreign markets for SMEs. Conversely, SMEs are important suppliers to large enterprises and in doing so add to the competitiveness of large enterprises on foreign markets.

In addition, of each euro of production for final demand, a larger share remains with the producing SME in terms of value added. On average, 41 cents remain with the SME compared to 32 cents at large enterprises. However, this seems due to a composition effect: SMEs are more often active in industries where the own value added in final production is higher. SMEs are less dependent on imports in the production of goods and services for final demand than large enterprises. This implies that SMEs might not benefit as much from importing less expensive and/or higher quality inputs as large enterprises, which might render them less competitive on international markets.

Previous work addresses heterogeneity in IO-tables by adding an extra split using enterprise characteristics different from the industry. Disaggregating IO-tables along the industry dimensions could also tackle the heterogeneity issue. However, it remains to be seen whether IO-tables that increase the granularity in this way are the best way to tackle heterogeneity, or that more elaborate procedures such as the approach proposed in this paper yield better results. The OECD expert group on extended SUTs (OECD 2014) anticipates that the optimal strategy varies even by country, since there is considerable country-level heterogeneity. As a case in point, China and Mexico have relatively large processing industries, which is why the multi-region input-output table of the OECD splits many industries of these countries into processing and non-processing industries (OECD 2015). In general, heterogeneity in IO-tables provides a promising avenue for further research. It will improve IO-tables and yield new policy-relevant insights depending on the type of heterogeneity (size class, ownership, processing yes/ no and so on) that is considered. 
development; SBS: structural business statistics; SME: small- and medium-sized enterprise; SUT: supply and use table; VAT: value-added tax.

\section{Authors' contributions}

SC, RVDW and PV compiled the extended supply use tables and input-output table and wrote the methodological sections. RH was a major contributor in writing the non-methodological part of the manuscript. OL, IVB and MVDB were major contributors in writing the non-methodological part of the manuscript and did the analysis and interpretation of the results. All authors read and approved the final manuscript.

\section{Author details}

${ }^{1}$ Statistics Netherlands, The Hague, Heerlen, Bonaire, The Netherlands. ${ }^{2}$ MetricsForTheFuture.com, Leiderdorp, The Netherlands. ${ }^{3}$ De Nederlandsche Bank, Amsterdam, The Netherlands. ${ }^{4}$ KU Leuven, Leuven, Belgium.

\section{Acknowledgements}

Views expressed are those of the authors and do not necessarily reflect official positions of Statistics Netherlands, De Nederlandsche Bank, KU Leuven or MetricsForTheFuture.com. We thank Gaaitzen de Vries, participants in the 24th International Input-Output Conference in Seoul, South Korea, participants in the Groningen Growth and Development Centre 25th Anniversary Conference and participants in the second, third and fourth meeting of the OECD Expert Group on extended SUTs in Paris, France, for valuable feedback and comments that improved the paper.Any errors that remain are the responsibility of the authors.

Competing interests

The authors declare that they have no competing interests.

\section{Availability of data and materials}

The supply-use table and the input-output table generated and analyzed during the current study can be found at the website of Statistics Netherlands.

Ethics approval and consent to participate

Not applicable.

Funding

Part of the research for this paper was financed by the Dutch Ministry of Economic Affairs.

\section{Appendix: Details on the methodology}

The information below is included here to adequately inform the reader who is interested in the technical details and who might want to replicate the process, whereas others might be only interested in the key features that are now described in the main text. The information is a summary of the papers by Chong et al. (2016b, c).

\section{About the delineation of SMEs}

First, enterprises under foreign control (multinational enterprises or MNEs) could jointly, at the international aggregate level of the parent company, still have less than 250 employees and thus in a strictly technical sense be an SME. However, while we observe that the Dutch enterprise has a foreign parent, we have no data on global group size. We adopt a conservative approach for all foreign-owned enterprises: Regardless of their global or domestic enterprise (group) size, they will not be assigned the SME status. The idea behind this choice is that regardless of the global group size, the MNE can rely on the global network of the foreign parent, with access to information, funds, networks, etc., and therefore the MNE will show more resemblance to a large enterprise than to an SME.

Second, domestically owned enterprise groups with less than 250 employees in the Netherlands could have subsidiary companies abroad rendering the international conglomerate too large to be considered an SME. Unfortunately, we do not know the full population of foreign subsidiaries nor do we have the exact information on global group size including these subsidiaries. However, it seems that this is a relatively small group. Using tax information and a model Lemmers (2014) estimates that the share of such Dutch SMEs in total exports of goods is only $0.2 \%$. We assumed that domestically owned 
enterprise groups with less than 250 employees in the Netherlands have less than 250 employees worldwide as well and that this assumption will not have a major impact on our results.

\section{Calculating total value added by industry size class cluster}

1. Remove outliers and calculate mean value added per employee of the responding enterprises by industry size class cluster;

2. Assign in each industry size class cluster the mean value added per employee of the responding enterprises to non-responding enterprises and enterprises not in the survey;

3. Calculate total value added by industry size class cluster by multiplying value added per employee with the number of employees at the enterprise level;

4. Use in each industry size class cluster the ratio of total value added reported by responding enterprises to calculated value added of all enterprises after imputation to obtain weighting factors. These are used to estimate the other variables from the Structural Business Statistics;

5. Aggregate the industry size class clusters (with industry and size class from the SBS) to the industry size class clusters that are to be used for the extended SUT;

6. Reconcile the data by industry size class cluster in such a way that the aggregates on industry level are consistent with the values by industry that national accounts used in its production process.

\section{Estimating information for the industries that are not covered by the SBS}

The information for these industries is estimated as follows:

- The industries agriculture and fishing are separated in size classes proportionally according to the number of employees in each industry size class cluster in the population registry. In doing so, we impose the same input-output structure on each size class within each industry.

- The industry forestry is separated in size classes by evaluating information from individual enterprises in this industry.

- The industries containing financial institutions, government, education and healthcare services are not separated in size classes, since the available statistical information does not allow for a solid separation of industries into industry size class clusters.

The industries culture, sports and recreation consist of a total of 20 underlying subindustries. These sub-industries are separated in size classes proportionally according to the number of employees in each industry size class cluster in the population registry, again imposing the same input-output structure on each size class within each subindustry. Note that some sub-industries consist of only large enterprises (e.g., lotteries and betting) and some consist only of small enterprises (e.g., arts). The information by 
size class of the 20 sub-industries is then aggregated to the level of industry size class clusters.

\section{Remaining additions and adjustments, also part of the regular SUT procedure}

- Holding companies in smaller size classes are not covered by the SBS. The financial figures are being estimated and divided proportionally over the various size classes of the industry of the holding companies.

- An estimate is made of the economic size of individuals building their own houses, growing crops, etc. These activities are solely assigned to small enterprises. The same holds for illegal activities.

- Remuneration in kind is usually reported by enterprises in the SBS as a current cost. This is adjusted in the compilation of the national accounts, since there it should be recorded as part of value added. The adjusted values are assigned to size classes proportionally.

- Cost of fraud, which is reported in the national accounts mainly as consumption of households instead of current costs for enterprises as in the SBS, is assigned to small enterprises.

- Research and development (R\&D) is reported by enterprises in the SBS as a current cost while in the national accounts framework it is considered an investment. The adjustment is made according to reported costs of R\&D in the SBS. The same holds for investments in other intangible assets.

- Financial intermediation services indirectly measured (FISIM). Banks usually do not charge a direct fee from their customers for their intermediation with loans, deposits, etc. Instead, they charge an indirect fee because there is a margin between the interest rate that they pay (or receive) themselves and the interest rate that the customer pays (or receives). In national accounts, this implicit fee is called FISIM. Following international agreed methodology (Eurostat 2013), FISIM is assigned to size classes proportionally to their production.

\section{More detail on transforming trade in goods data to national accounts data}

About $87 \%$ of the import value and $80 \%$ of the export value in the ITG statistics can be assigned to enterprises in the GBR, and therefore to an industry size class cluster. The remaining value cannot be matched to enterprises in the GBR. The main reason why ITG units do not match to the GBR is that several large multinationals register their trade for administrative reasons at the Dutch VAT number of a nonresident parent or subsidiary instead of the VAT number of the resident enterprise. The nonresident enterprises are registered for VAT purposes in the Netherlands but they do not have a physical establishment in the Netherlands; therefore, they do not appear in the GBR and a match between this ITG unit and the GBR is impossible. Since their trade 
Table 5 Example of the distribution of imports of a product by destination industry

\begin{tabular}{|c|c|c|c|c|c|c|}
\hline & Imports in ITG & Use in SUT & Step 1 & Step 2 & Step 3 & Step 4 \\
\hline Furniture industry & 20 & 40 & 20 & 20 & 5 & 25 \\
\hline Wholesale & 40 & 10 & 10 & 0 & 0 & 10 \\
\hline Household consumption & 0 & 20 & 0 & 20 & 5 & 5 \\
\hline Subtotal (excl re-exports) & 60 & & & 40 & & \\
\hline Re-exports & 0 & 20 & 20 & 0 & & 20 \\
\hline Total & 60 & 90 & 50 & 40 & 0 & 60 \\
\hline Redistributed & - & - & 10 & - & - & - \\
\hline
\end{tabular}

is actually trade of a resident enterprise, it is included in ITG statistics. Note that trade that is not assigned to an industry size class cluster in ITG has to be assigned to such a cluster in the SUT.

After assigning trade from the trade statistics (ITG) to an industry size class cluster based on the industry and size class of the trading enterprise, we adopt a stepwise approach, by product, to assign it to the proper industry size class cluster in the SUT. Below, we explain how to do this for imports; the method for exports is similar. The method is illustrated in Table 5.

1. Comparison of imports (in ITG) and use (in SUT) in each industry size class cluster:

a. If use exceeds imports, the assumption is that all imports by this industry size class cluster are being used by itself

b. If imports exceed use, the assumption is that the industry size class clusters complete imports are being used by itself and the additional imports are used by other industry size class clusters. This yields a remainder of imports that needs to be redistributed over industry size class clusters where use exceeds imports.

2. Remaining use by industry size class cluster is calculated, i.e., the part of use that is not imported.

3. Remaining imports from step 2 and unassigned trade and trade below the threshold (that has no product detail) are proportionally redistributed over industry size class clusters with use exceeding imports based on their remaining use as calculated in step 2.

4. Total imports by industry size class cluster are calculated by adding imports from steps 1 and 3 .

\section{More detail on transforming trade in services data to national accounts data}

Trade in services by larger traders is registered at the enterprise group level rather than the enterprise level. Using additional tax information, trade figures are assigned to enterprises. This improves the assignment to the correct industry size class cluster, since that of the enterprise is more specific than that of the enterprise group. Another complication is that unlike trade in goods, which is observed for the population of enterprises, trade in services data are only collected for a sample of service traders. Moreover, 
the sampling strata used to sample traders are specific to the trade in services statistic and hence do not correspond to the industry size class clusters of the extended SUT. To accommodate for this, a two-step approach is taken. In a first step, survey weights are used to redistribute services trade across industries and size classes. In a second step, these weights are adjusted to assure that the distribution of services trade matches the distribution of service traders by size class from the GBR.

Finally, the treatment of travel differs between imports (Dutch residents traveling abroad) and exports (foreigners traveling to the Netherlands). Imports of travel services are assigned to industry size class clusters based on reported costs in the SBS. Exports of travel services are derived from the Inbound Tourism Survey. Spending by visiting tourists is allocated to products and connected to the main producing industry of the products concerned. In a subsequent step, expenses are distributed over size classes based on output.

\section{More detail on the input-output analysis}

The basic input-output model (Miller and Blair 2009) can be expressed in matrix form as:

$$
x=Z i+f=A x+f
$$

Or, in words, each industry's total output $(x)$ is equal to the summation of intermediate $(Z)$ and final demand $(f)$ for its product, with $i$ being a column vector of 1 's and $A$ representing a matrix of direct production coefficients. Rewriting this equation gives us the basic formula for input-output analysis:

$$
x=(I-A)^{-1} f=L f
$$

where $L$ is known as the Leontief inverse; a matrix element $L_{i j}$ expresses the amount of output industry $i$ needs to supply, both directly and indirectly, for one unit of production for final demand of industry $j$. Define vector $v$ as a vector representing the value added generated per euro of output by industry (and $\hat{v}$ as the diagonal matrix of $v$ ), so that total value added by industry $(V)$ can be expressed as follows:

$$
V=\hat{v} x=\hat{v}(I-A)^{-1} f=\hat{v} L\left(f_{\mathrm{d}}+f_{\mathrm{e}}\right)
$$

where following Su et al. (2010), $f_{\mathrm{d}}$ denotes the vector of domestic final demand and $f_{\mathrm{e}}$ the vector of foreign final demand (exports). Note that $\hat{v} L$ yields a square matrix $M$, of which the element $\mathrm{M}_{i j}$ represents the amount of value added generated by industry $i$ for one unit of production for final demand of industry $j$. Total value added embodied in exports by industry can then be easily expressed as:

$$
V_{\mathrm{e}}=\hat{v} L \hat{f}_{\mathrm{e}} i
$$

And analogously, total value added generated for domestic final demand can be expressed as:

$$
V_{\mathrm{d}}=\hat{v} L \hat{f}_{\mathrm{d}} i
$$


Received: 6 August 2018 Accepted: 15 February 2019

Published online: 26 February 2019

\section{References}

Baldwin R (2016) The great convergence. Information technology and the new globalization. The Belknap Press of Harvard University Press, Cambridge

Bernard A, Jensen J, Redding S, Schott P (2007) Firms in international trade. J Econ Perspect 21 (3):105-130

Bernard A, Jensen J, Redding S, Schott P (2012) The empirics of firm heterogeneity and international trade. Ann Rev Econ 4(1):283-313

Bernard A, Moxnes A, Saito Y (2015) Production networks, geography and firm performance. NBER Working Paper No. 21082, National Bureau of Economic Research. Journal of Political Economy, forthcoming 2018

Beverelli C, Koopman R, Kummritz V, Neumuller S (2016) Domestic Foundations of Global Value Chains. Working Paper

Chong S, Van Beveren I, Verbiest P, Van der Wal R (2016a) Input-outputtabel voor het MKB en grootbedrijf 2012. https:// www.cbs.nl/-/media/_excel/2016/23/io-agt_mkb_max6juni2016.xlsx. Accessed 4 Aug 2018

Chong S, Van Beveren I, Verbiest P, Van der Wal R (2016b) Een IO-tabel voor het MKB en grootbedrijf. Statistics Netherlands, Dutch

Chong S, Van Beveren I, Verbiest P, Van der Wal R (2016c) De rol van het midden- en kleinbedrijf in de Nederlandse economie. Statistics Netherlands, Dutch

De Bontridder - De Steur M, Packbier W, Smit R (2015) Trends in internationale handel, $1^{\mathrm{e}}$ kwartaal 2015. In: Internationaliseringsmonitor 2015, derde kwartaal. Statistics Netherlands, Dutch

Dietzenbacher E, Los B (2002) Externalities of R\&D expenditures. Econ Syst Res 14(4):407-425

European Commission (2013) Mission for growth: EU businesses benefit from emerging markets. In: Enterprise \& industry magazine nr 15, Feb 2013

European Commission (2018) What is an SME? http://ec.europa.eu/growth/smes/business-friendly-environment/smedefinition_en. Accessed 4 Aug 2018

Eurostat (2008) Eurostat manual of supply, use and input-output tables. Eurostat, Luxemburg

Eurostat (2013) European system of accounts, ESA 2010. Eurostat, Luxemburg

Hummels D, Rapoport D, Yi KM (1998) Vertical specialization and the changing nature of world trade. Econ Policy Rev 4(2):79-99

Hummels D, Ishii J, Yi KM (2001) The nature and growth of vertical specialization in world trade. J Int Econ 54(1):75-96

Johnson R, Noguera G (2012) Fragmentation and trade in value added over four decades. NBER Working Paper No.

18186, National Bureau of Economic Research. Also published in 2017 as Review of Economics and Statistics 99(5), 896-911

Kneller R, Pisu M (2011) Export barriers: What are they and who do they matter to? World Econ 34(6):893-930

Kummritz V (2016) Do global value chains cause industrial development? CTEl Working Paper No. 2016-01, Centre for Trade and Economic Integration

Lemmers O (2014) The share of SMEs in trade and investments; three delineations of SMEs. Statistics Netherlands, Dutch

Miller RE, Blair PD (2009) Input-output analysis: foundations and extensions, 2nd edn. Cambridge University Press, Cambridge

OECD (2014) Terms of reference OECD expert group on extended supply-use tables. OECD, Paris

OECD (2015) Trade in value added (TIVA) indicators - guide to country notes. OECD, Paris

Piacentini M, Fortanier F (2015) Firm heterogeneity and trade in value added. OECD, Paris

Pommée M, Van Dalen J (1997) Een input-outputtabel naar grootteklasse van de Nederlandse economie voor 1992: kleine, middelgrote en grote bedrijven. Statistics Netherlands, Dutch

Smeets R, Creusen H, Lejour A, Kox H (2010) Export margins and export barriers. Uncovering market entry costs of exporters in the Netherlands. CPB Document 208. CPB

Statistics Denmark and OECD (2017) Nordic countries in global value chains

Statistics Netherlands (2017) Gross National Income Inventory (ESA 2010) 2010 The Netherlands

Su B, Huang HC, Ang BW, Zhou P (2010) Input-output analysis of $\mathrm{CO}_{2}$ emissions embodied in trade: the effects of sector aggregation. Energy Econ 32:166-175

Tang H, Wang F, Wang Z (2016) Extending the input-output table based on firm-level data. CESIfo Working Paper No. 5811

Timmer M, Erumban A, Los B, Stehrer R, De Vries GJ (2014) Slicing up global value chains. J Econ Perspect 28(2):99-118

USITC (2010) Small and medium-sized enterprises: characteristics and performance. United States International Trade Commission, Investigation No. 332-510, USITC Publication 4189

USITC (2014) Trade barriers that U.S. small and medium-sized enterprises perceive as affecting exports to the European Union. Investigation No. 332-541, USITC Publication 4455

Van Den Berg M (2014) Does internationalization foster firm performance? Dissertation, University of Utrecht

Van Den Berg M, Van Marrewijk C (2017) Imports and productivity: the impact of geography and factor intensity. J Int Trade Econ Dev 26(4):425-450

Wagner J (2007) Exports and productivity: a survey of the evidence from firm-level data. World Econ 30(1):60-82

Wagner J (2012) International trade and firm performance: a survey of empirical studies since 2006. Rev World Econ 148:235-267

Wymenga P, Plaisier N, Vermeulen J (2013) Study on support services for SMEs in international business. ECSIP Consortium, Rotterdam

Yang C, Dietzenbacher E, Pei J, Chen X, Zhu K, Tang Z (2015) Processing trade biases the measurement of vertical specialization in China. Econ Syst Res 27(1):60-76 